\title{
Estado, território e reestruturação produtiva na metropóle fluminense
}

État, territoire et restructuration productive dans la métropole fluminense State, territory and productive restructuration in the fluminense metropolis Estado, territorio y re-estructuración productiva en la metrópoli fluminense

\section{Regina Celi Pereira}

\section{OpenEdition}

Journals

Edição electrónica

URL: http://journals.openedition.org/espacoeconomia/390

DOI: 10.4000/espacoeconomia.390

ISSN: 2317-7837

\section{Editora}

Núcleo de Pesquisa Espaço \& Economia

Refêrencia eletrónica

Regina Celi Pereira, «Estado, território e reestruturação produtiva na metropóle fluminense », Espaço e Economia [Online], 3 | 2013, posto online no dia 19 dezembro 2013, consultado o 30 abril 2019. URL : http://journals.openedition.org/espacoeconomia/390; DOI : 10.4000/espacoeconomia.390

Este documento foi criado de forma automática no dia 30 Abril 2019.

(C) NUPEE 


\title{
Estado, território e reestruturação produtiva na metropóle fluminense
}

\author{
État, territoire et restructuration productive dans la métropole fluminense \\ State, territory and productive restructuration in the fluminense metropolis \\ Estado, territorio y re-estructuración productiva en la metrópoli fluminense
}

\section{Regina Celi Pereira}

\section{Introdução}

1 Estado e capital privado têm empreendido vasto programa de investimentos capazes de oferecer as condições materiais necessárias ao processo de transformação do território brasileiro em espaço de economia global.

2 O processo de reestruturação produtiva em curso constitui um fator definidor para a incorporação de parcelas do território nacional anteriormente excluídas do processo de valorização do capital. A dispersão das atividades tradicionalmente concentradas na área core do País contribuiu para a transformação das estruturas produtivas das diversas regiões, resultando em uma maior diferenciação do espaço nacional.

3 Na medida em que acolhe os vetores da racionalidade dominante, expressiva da nova escala da produção, circulação e consumo vinculada à fase contemporânea da acumulação, o território torna-se cada vez mais artificializado e os lugares, em consequência, cada vez mais especializados. Cada ponto do território modernizado é chamado a oferecer aptidões específicas à produção.

4 Nos lugares, repercutem de maneira crescente os embates entre os diversos atores, numa disputa em que os portadores das velocidades extremas comandam a disseminação dos sistemas de engenharia necessários à acumulação, roubando às coletividades o controle do seu destino.

5 Cabe ressaltar, no entanto, que essa relativa desconcentração não rompeu completamente com a tradicional polarização da Região Concentrada. Concorrem para o processo de 
concentração dos investimentos nas áreas já dinâmicas e competitivas do País os novos requisitos locacionais da acumulação flexível, como: a busca por melhores ofertas de recursos humanos qualificados, maior proximidade com centros de produção de conhecimento e tecnologia, maior e mais eficiente dotação de infraestrutura econômica, proximidade com os mercados consumidores de mais alta renda e, sem dúvida, a proximidade de um conjunto de empresas prestadoras de serviços especializados dirigidos à atividade industrial.

Nesse contexto, as metrópoles, aproveitando-se de vantagens locacionais historicamente construídas, tanto no que se refere à concentração de atividades de produção e de administração como no que diz respeito à inscrição espacial de funções culturais especializadas, tendem a manter a sua posição privilegiada. Demonstrando a presença de interesses econômicos e políticos que direcionam a atualização na face contemporânea do capitalismo, acumulam novas funções, ampliam sua área geográfica de influência, transformam-se em pontos nodais das modernas redes.

7 Através deste artigo, buscaremos fundamentar alguns conceitos centrais de nossa reflexão, bem como destacar a posição estratégica assumida pelo Estado brasileiro e pelos agentes privados no que se refere ao planejamento territorial e aos investimentos vinculados à reestruturação econômica e às exigências de competitividade da atual fase de acumulação capitalista, no espaço da região metropolitana do Rio de Janeiro. Acreditamos que as mudanças em curso lançam a metrópole em um processo de revitalização econômica e de integração territorial totalmente nova, que, além torná-la mais coesa, transborda suas fronteiras, articulando-a com áreas dinâmicas do interior do estado através de complexos fluxos que se processam em cadeias produtivas articuladas de forma não hierárquica nas escalas local, regional e global.

\section{Consideração sobre o Estado e o uso do território pelo capital}

8 A análise do Estado como forma institucional do poder político territorializado requer a consideração das complexas correlações de forças constitutivas da sociedade a partir da qual este se institui. o exercício do poder supõe assimetrias na posse de meios e estratégias, e o território é tanto um meio como uma condição de possibilidade de algumas dessas estratégias (Castro, 2005).

Historicamente, a formação do Estado está diretamente associada ao surgimento da constitucionalidade burguesa. Segundo Harvey (2005), o Estado burguês confere um ambiente seguro ao desenvolvimento do capitalismo, uma vez que mobiliza instrumentos capazes de fomentar e defender os interesses dos atores econômicos, tais como: a gestão das fronteiras alfandegárias, a política monetária e as estruturas institucionais de mercado e de regulação da relação entre classes.

10 As teorias clássicas, sejam de porte liberal ou marxista, sempre reconheceram um papel central dos Estados na estruturação da economia mundial. Porém, nas últimas décadas foram inúmeros os discursos que argumentavam que o Estado moderno é uma instituição em processo de dissolução.

11 Para Font e Ruf (2006), embora possamos identificar processos de transferência de competências tradicionais do Estado para instâncias superiores, globais, supraestatais ou macrorregionais, e fluxos de soberania para escalas inferiores, mais estritamente locais, 
seria errôneo interpretar essa perda de controle como uma cessão involuntária. Segundo esses autores,

“[...] contrariamente, os estados participam ativamente da abertura de mercados comerciais e financeiros, bem como da descentralização da produção, já que isso era fundamental para não ficar à margem dos processos de reforma econômica global que provocam exclusões políticas, sociais e econômicas radicais" (Font e Ruf, 2006:109)

12 Entre os protagonistas mais importantes nesse jogo contraditório da globalização está o Estado-nação. Este, movido por interesses e forças políticas conflitantes, atualiza constantemente suas estratégias territoriais e renova o seu papel político e econômico diante das sucessivas lógicas da acumulação. No contexto do neoliberalismo econômico, praticamente todos os Estados do mundo põem-se hoje em marcha para criar um ambiente de negócios atraente aos novos fluxos de capital, através da promoção de arranjos institucionais conjugados à instalação de certa infraestrutura física no espaço e à criação ou renovação de suas forças produtivas como um todo.

A geografia histórica do capitalismo se expressa através do convívio entre a relativa fixidez, correspondente à lógica peculiar do poder territorial e seus sucessivos ciclos de interferência, e a fluida dinâmica da acumulação do capital no espaço e no tempo (Harvey, 2005).

14 No se refere à dinâmica espacial do capital, Harvey (2005) afirma que as trocas de bens e serviços quase sempre envolvem mudanças de localização e definem um conjunto de interseções de movimentos espaciais que estão sujeitos a fricção da distância. Historicamente, a atividade capitalista produz o desenvolvimento desigual e reforça as diferenciações e especializações espaciais.

15 As vantagens decorrentes da localização desempenham para os capitalistas individuais um papel semelhante aos derivados das vantagens tecnológicas. Conforme o autor, os processos de acumulação de capital estão em constante expansão, rompendo com toda tendência ao equilíbrio. A derrubada de barreiras espaciais e a abertura de novas modalidades de movimento, de espaços e de mercados é uma constante no processo de acumulação.

16 O comportamento competitivo gera um estado de instabilidade na distribuição espacial das atividades em decorrência da busca por localizações superiores, conduzindo ao movimento permanente da paisagem geográfica da produção, da distribuição e do consumo. A localização espacial confere vantagens monopolísticas, ampliando a disputa pelo controle de localizações estratégicas capazes de conferir diferenciais de competitividade.

De acordo com o autor, as inovações voltadas para a remoção das barreiras espaciais têm tido imensa significação na história do capitalismo, transformando-a em uma questão deveras geográfica, pois as barreiras espaciais só podem ser reduzidas por meio da produção de espaços particulares. Em suas palavras,

“[...] a produção, a reestruturação e o crescimento da reestruturação espacial são muito problemáticos e caros, sendo prejudicados pela necessidade de vastos investimentos em infraestruturas físicas que não podem ser levadas para outro lugar e em infraestruturas sociais que sempre mudam com lentidão" (Harvey, 2001:212).

18 Note-se que o domínio do espaço sempre foi um aspecto vital da luta de classes. Nos termos de Harvey (2001), as alterações na organização espacial redistribuem o poder 
social, e a capacidade de influir na produção de espaço constitui um importante meio de aumento do poder social.

A lógica contemporânea da acumulação envolve o controle e a subordinação do território, tornando-o cada vez mais fluido aos interesses dos atores hegemônicos transnacionais. No entanto, o movimento fluido sobre o território só pode existir mediante a instalação de ativos fixos e imobilizados no espaço. O Estado é reconhecidamente o ente político mais importante do planejamento territorial. Ao mobilizar seus recursos para dotar o espaço dos conteúdos técnicos e funcionais exigidos pela acumulação, o Estado induz a diferenciação e reforça as desigualdades entre os lugares.

\section{O controle hegemônico do território usado}

20 A noção de território privilegiada em nossas reflexões é a de território usado, sinônimo de espaço geográfico, de espaço banal, conforme as reflexões desenvolvidas por Milton Santos $(1994,2000)$.

21 Na perspectiva do autor, o território usado, visto como uma totalidade, revela a estrutura global da sociedade e a própria complexidade do seu uso, uma vez que "constitui-se como um todo complexo, onde se tece uma trama de relações complementares e conflitantes", convidando-nos "a pensar processualmente as relações estabelecidas entre o lugar, a formação socioespacial e o mundo" (Santos 2000:3).

O território usado é a expressão das relações sociais e dos interesses estratégicos dos diferentes atores sociais. São os complexos arranjos derivados da multiplicidade de ações e do convívio dos atores hegemônicos com os hegemonizados que irão conferir aos lugares a sua singularidade. De acordo com o autor, para os atores hegemonizados o território constitui um abrigo, ao passo que para os atores hegemônicos o território usado é um recurso, uma garantia de realização dos seus interesses particulares.

Na disputa entre os diversos atores, o território "é marcado por um cotidiano compartido, mediante regras que são formuladas e reformuladas localmente" e um "acontecer hierárquico", "imposto de fora, comandado por uma informação privilegiada, uma informação que é segredo e é poder", comportando uma dialética que "se afirma mediante um controle local" da técnica da produção e um controle remoto da parcela política da produção" (Santos, 1994:17).

24 Segundo o autor, "o território são formas, mas o território usado são objetos e ações" (Santos, 1994:16). Cabe, então, lembrar que os sistemas técnicos, também denominados sistemas de objetos ou fixos, funcionam como suporte - mas também como condicionantes - para sistemas de ação que se desenvolvem a partir das relações sociais de produção e da dinâmica social.

25 As características técnicas e organizacionais assumidas pelos fixos abrigam uma tipologia de fluxos que possuirão uma escala tanto mais elevada quanto maior for o grau de inovação presente nos objetos. Na atualidade, segundo Santos (1994a), esses sistemas técnicos tendem a tornar-se cada vez mais unificados e mutuamente dependentes. Essa unidade não é apenas técnica, mas também organizacional e se traduz em uma tendência mundial que tem tido seu potencial expandido à medida que o sistema capitalista se mundializa e consolida a interdependência entre os lugares. 
Com a crescente internacionalização do capital, e sua valorização à escala das regiões do mundo em que há recursos ou mercados, a concorrência entre firmas, e também entre lugares, atinge novos patamares. A competitividade em nível mundial alimenta a demanda diuturna de mais ciência, de mais tecnologia, de soluções organizacionais e políticas que assegurem o aumento da produtividade e da lucratividade dos agentes hegemônicos.

Os novos sistemas técnicos são imprescindíveis para a eficácia da ação empresarial e para a mediação de relações globais seletivas. Trata-se da administração apoiada na agilidade dos fluxos e na fluidez do território. Sob o comando dos atores hegemônicos contemporâneos, muitas vezes alheios aos interesses do lugar, novas articulações são impostas às atividades econômicas e sociais.

A difusão de elementos da atual frente de processos de modernização resulta em configurações e hierarquias territoriais baseadas nas possibilidades de processamento e difusão de mensagens e ordens que orientam os investimentos, e na fluidez do território posto a serviço da competitividade através da adição permanente de uma materialidade funcional capaz de suprimir as rugosidades hostis aos processos de acumulação.

Através dos crescentes investimentos em ciência, tecnologia e informação, determinados lugares concentram os suportes técnicos que viabilizam as estratégias acionadas pelos atores hegemônicos, tornando-se, com isso, espaços de comando, densos de fluxos e de informação, com intenso poder de atração de atividades e investimentos. Nesse processo, segmentos do território afirmam-se, reforçando desigualdades sociais, como lugares "luminosos", enquanto outros permanecem “opacos” (Santos, 1993).

Os atores hegemônicos comandam operações econômicas que rompem limites entre setores produtivos e barreiras espaçotemporais apoiados nesses sistemas técnicos de informação. Graças à unicidade das técnicas, esses atores emitem e controlam fluxos diversos relacionados aos seus interesses específicos, além de subordinarem receptores localizados em pontos remotos. Impelindo ações globais, impulsionam o motor único da acumulação e da exploração do trabalho.

1 De pontos privilegiados do território articulado em rede emanam ordens que impõem o acontecer hierárquico indispensável à acumulação, atravessando verticalmente formas solidárias locais historicamente construídas, acirrando os conflitos entre "um espaço local, vivido por todos os vizinhos, e um espaço global” (Santos, 1994:18), obediente a uma lógica racional exógena, emanada de um controle distante.

\section{Estado, território e metrópole: do planejamento estatal centralizado ao comando integrado do território pelo capital}

32 Historicamente, o Estado brasileiro tem se colocado como o principal agente de implementação das reformas e das modernizações necessárias ao processo de acumulação capitalista, intervindo diretamente sobre o território e a sociedade através do planejamento governamental.

A ação do Estado pode ser verificada nos investimentos diretos na produção industrial, na qualificação técnica do espaço através da instalação de infraestruturas, na integração do nacional através das redes de transportes e comunicação, nos planos de desenvolvimento 
econômico, nos programas de produção de energia, no conjunto de ações vinculadas à regulamentação das relações entre capital e trabalho e de formação e qualificação da força de trabalho, entre outros aspectos.

No que diz respeito ao desenvolvimento urbano e regional, a preocupação do Estado, segundo Lencione (2008), pode ser situada nos anos 1960 e 1970, como decorrência do crescimento acelerado da população urbana, do desenvolvimento de uma estrutura industrial extremamente concentrada, e do agravamento dos denominados problemas urbanos, relacionados à insuficiência e má qualidade dos transportes, do saneamento e da habitação.

Nos anos 1970, em pleno regime militar, foram instituídas as Regiões Metropolitanas, cuja criação tinha como pressupostos essenciais o fato de serem formadas por mais de um município, com um município-núcleo, e o fato de serem objeto de programas especiais, levados adiante por organismos regionais especialmente criados, com a utilização de recursos federais.

Conforme a autora, nesse período a Teoria dos Polos de Desenvolvimento, de Peroux (1973), teve grande influência nos discursos e ações dos organismos de governo. Sob essa influência, as regiões metropolitanas ganharam destaque, pois eram consideradas polos estruturadores do ordenamento territorial. As metrópoles deveriam impulsionar o desenvolvimento econômico, irradiando-o pelo território nacional, segundo sua condição hierárquica e o grau de importância econômica que tinham na rede urbana nacional.

Rompendo com as expectativas geradas, o desenvolvimento interno dessas regiões metropolitanas processou-se de maneira extremamente desigual. Além disso, a sobreposição de ações setoriais desenvolvidas de forma separada não permitiu a integração coordenada das políticas públicas, gerando o agravamento dos problemas urbanos.

38 A partir da década de 1980, com o aprofundamento da crise econômica, social e fiscal, os organismos de planejamento sofrem com a redução expressiva dos investimentos do Estado. Com o advento do neoliberalismo e os processos de globalização nos anos 1990, o mercado -- ou, melhor, o poder dos grandes grupos econômicos -- submete o poder do Estado-nação e emerge como força hegemônica na reestruturação do território (Lencioni, 2008).

39 Conforme essa autora, a cidade do século XXI está inserida em uma nova lógica da reprodução do capital e em um contexto de refluxo da ação do Estado. Refletir sobre a metrópole nos dias atuais conduz à necessidade de novos aportes teóricos, pois a metrópole contemporânea é uma espécie de manifestação socioespacial da globalização (Lencioni, 2006).

40 Estamos diante de um processo de metropolização do espaço, correspondente a um momento mais avançado do processo de urbanização. Em outros termos, independentemente do porte da cidade, esta pode apresentar características, como algumas condições gerais de produção e determinados serviços, que, anteriormente, eram exclusivas das metrópoles.

41 As antigas metrópoles, ao mesmo tempo em que renovam suas áreas urbanas, estendem sua área territorial, incorporando novas cidades e formando um aglomerado urbano que constitui um epicentro de fluxos de capital e dos grandes grupos econômicos estruturados em rede. Trata-se, segundo a autora, da cidade-região, expressão da nova escala de 
processos e relações sociais que se mesclam e integram, através das modernas redes de informação e de circulação, o local, o regional e o global.

\section{Novos rumos da metrópole fluminense}

Conforme mostra Oliveira (2011), as principais transformações no estado do Rio de Janeiro podem ser verificadas no início dos anos 1990, a partir de mudanças específicas ocorridas nas bases técnicas do interior do estado, com destaque para o Norte fluminense, onde a economia agroindustrial sucroalcooleira cede espaço às atividades extrativistas $\mathrm{e}$ logísticas vinculadas à expansão da indústria de petróleo e gás. E, também, para o Sul do estado, onde a base isolada do setor siderúrgico, liderado pela Companhia Siderúrgica Nacional (CSN), integra-se a um complexo polo metal-mecânico e siderúrgico vinculado às indústrias automobilísticas e às atividades portuárias da região.

Durante os anos 1990, esses novos espaços econômicos ganham expressão e passam a influir de modo positivo na reversão do quadro de estagnação econômica que perdurava no estado, com alguns reflexos econômicos e sociais na região metropolitana, particularmente com a reativação de alguns estaleiros da indústria naval. Naquela década, a atividade que mais gerava expectativa na região metropolitana era o Polo Gás-Químico, associado à Refinaria de Caxias (Reduc), que, segundo nosso autor, pouco avançou, em virtude da insuficiência das redes técnicas e de logística.

Mapa 1 : Região Metropolitana do Rio de Janeiro



CRÉdITOS : ELABORADO A PARTIR DE BASE CARTOgRÁficA DO IBGE

Somente a partir da segunda metade do século XXI, como resultado da intervenção do Governo Federal, os efeitos da nova economia do interior passam a ter rebatimentos significativos na região metropolitana, imprimindo uma nova lógica ao uso do território da região e seu entorno. 

conduziram à construção imediata do Arco Metropolitano, com o objetivo de garantir acesso rápido entre o Comperj e o Porto de Itaguaí. Complementarmente, as obras de duplicação do trecho da BR-101 entre as cidades do Rio de Janeiro e Mangaratiba foram concluídas e puderam facilitar o acesso das indústrias do município do Rio de Janeiro ao Porto.

50 A finalização das obras dessa rodovia resultará na integração do Porto de Itaguaí à malha rodoviária nacional; na ligação entre os cinco eixos rodoviários beneficiados pelo projeto sem necessidade de conexão via Avenida Brasil e Ponte Presidente Costa e Silva, desviando assim o fluxo de tráfego das principais vias de acesso à capital; no aumento de acessibilidade e da mobilidade populacional dos municípios próximos ao Arco Metropolitano.

51 Atualmente, todas as estradas federais que cortam o estado (BR-116, BR-040 e BR-101) convergem para a cidade do Rio de Janeiro. A construção do Arco Metropolitano romperá com a centralização da circulação de mercadorias e cargas, estimulando maior integração dos municípios periféricos e reduzindo os custos derivados da fricção da distância.

Conforme podemos observar no mapa a seguir, o projeto do Arco Rodoviário Metropolitano do Rio de Janeiro (AMRJ) abrange trechos de rodovias perpendiculares aos grandes eixos rodoviários que convergem para o município do Rio de Janeiro e atravessam a Baixada Fluminense - notadamente a BR-101/RJ Sul, a BR-116/RJ Sul, BR-040/RJ, BR-116/RJ Norte e BR-101/RJ Norte. 


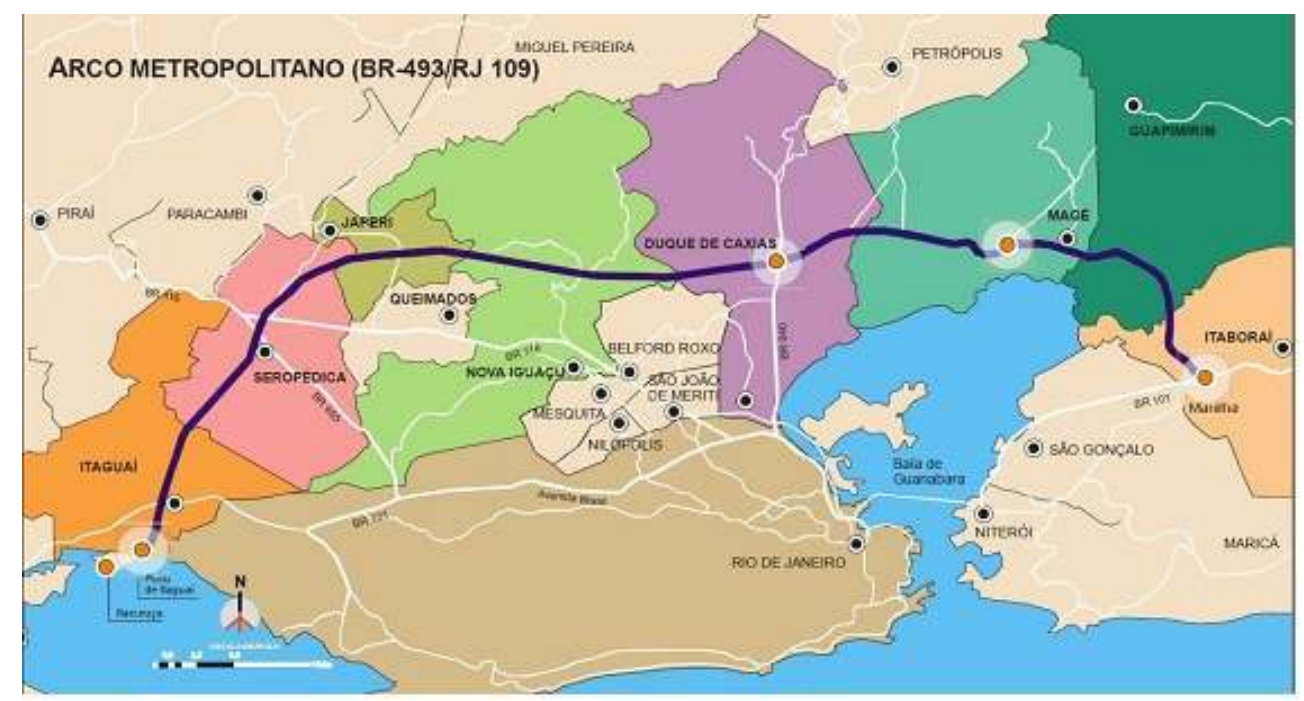

FONTE: FIRJAN,SITE, 2011

Segundo a Firjan (2008), a região de influência do Arco Metropolitano se estende por sete estados. Utilizando o Porto de Itaguaí, os quatro do Sudeste teriam uma redução maior no custo do transporte, com destaque para a região do Vale do Paraíba, tanto no lado do Rio de Janeiro quanto no de São Paulo, onde essa economia poderá chegar a 20\%. Outros dois estados, apesar de mais distantes (Mato Grosso do Sul e Goiás), ainda teriam uma redução de até $2,5 \%$ no frete. Além disso, o Arco trará uma economia de cerca de $3 \%$ no custo de transporte para a ligação entre o Comperj e a cidade de São Paulo.

Os municípios no entorno do Arco Metropolitano do Rio de Janeiro terão redução de 15\% a $20 \%$ nos custos de transporte no acesso a Itaguaí. Portanto, a integração do Porto de Itaguaí à malha rodoviária e ferroviária provocará efeitos notáveis na redução de custo para seus usuários, garantindo a competitividade do comércio portuário nacional e internacional.

Entre outros investimentos em curso, destacamos a instalação da Companhia Siderúrgica do Atlântico (CSA) no bairro de Santa Cruz, em operação desde junho de 2010. A construção ocupa uma área de aproximadamente 10 milhões de metros quadrados. A empresa beneficiará o minério retirado no estado de Minas Gerais pela Companhia Vale do Rio Doce, uma das sócias do empreendimento, junto com o grupo ThyssenKrupp, que é o controlador.

Conforme Oliveira (2011), a recuperação e a dinamização do Distrito Industrial de Santa Cruz já são realidade, podendo-se mesmo falar de um novo polo siderúrgico em vias de instalação. A região também tem atraído outras empresas do ramo petroquímico, como a Petroquisa, subsidiária da Petrobras, que pretende instalar uma unidade no município de Seropédica. Do outro lado, nos municípios cortados pela Presidente Dutra, rodovia que também está em fase de duplicação, podemos ver a presença de grandes galpões de empresas de logística intermodal, além de depósitos de grandes redes varejistas. 


\section{Considerações finais}

57 A acelerada transformação no uso do território da metrópole fluminense é uma realidade em curso. A articulação peculiar entre o Estado e o capital privado confere viabilidade crescente aos fluxos de mercadorias e capitais, articulando pontos nevrálgicos de produção e garantindo a fluidez através das modernas redes de circulação.

A nova escala da produção amplia o raio dos processos metropolitanos e integra o território através de um complexo emaranhado de fluxos que se processam simultaneamente nas escalas local, regional e global. Estamos diante de processos de metropolização que se formam em comunhão com os interesses do capitalismo globalizado.

Porém as mudanças na esfera da produção devem ser consideradas no contexto da relação dialética que envolve os interesses do capital, do Estado e, sobretudo, da sociedade. Além das verticalidades apoiadas nas modernas redes que atendem aos interesses privados dos atores hegemônicos, o território usado corresponde ao espaço banal, o espaço usado por todos, e deve ser produzido de acordo com os interesses comuns aos atores sociais em questão.

60 Não podemos ocultar o caráter conflituoso que envolve o domínio do espaço sob a forma exterior solidária de um pretenso interesse público de desenvolvimento econômico, que muitas vezes não encontra rebatimento significativo nas comunidades locais.

61 É preciso analisar o impacto decorrente desses processos de modernização. Muitos desses investimentos têm rompido violentamente com formas solidárias de reprodução. Isso sem falar nos danos ambientais, nas novas demandas geradas em termos de infraestruturas e serviços urbanos derivadas do crescimento populacional acelerado, induzido por novas formas de ocupação do território.

Não somos ingênuos de pensar que todos os resultados são perversos. Ao contrário, somos de opinião que essas novas formas de organização são necessárias para a inserção competitiva do País na economia globalizada e certamente trarão excelentes resultados em termos econômicos e sociais. Mas sustentamos a necessidade da criação de mecanismos institucionais de gestão que operem em uma escala integrada e sejam capazes de conduzir ações vinculadas aos interesses das comunidades, a fim de que o crescimento se transforme em desenvolvimento e não em mais exclusão.

\section{BIBLIOGRAFIA}

CASTRO, I. E. O poder e o poder político como problemas. In: CASTRO, I. E. Geografia e política: território, escalas de ação e instituições. Rio de Janeiro: Bertrand Brasil, 2005.

FIRJAN. Estudos para o desenvolvimento do Estado do Rio de Janeiro. Avaliação dos impactos logísticos e socioeconômicos da implantação do Arco Metropolitano do Rio de Janeiro. Edição nº3, 2008. 
FONT, J. N. e RUFF, J. V. Geopolítica, identidade e globalização. São Paulo: Annablume, 2006.

HAESBAERT, R. 0 mito da desterritorialização: do fim dos territórios à multiterritorialidade. Rio de Janeiro: Bertrand Brasil, 2004.

HARVEY, D. Condição pós-moderna. São Paulo: Edições Loyola, 2001.

HARVEY, D. O novo imperialismo. São Paulo: Edições Loyola, 2005.

LENCIONI, S. Da cidade e sua região à cidade-região. In: SILVA, J.B., LIMA, L.C. ELIAS, D. (orgs.). Panorama da geografia brasileira. São Paulo: Annablume, 2006.

LENCIONI, S. Da metrópole como estratégia desenvolvimentista à metrópole como sobrevida do capitalismo. Santiago: PUC-Chile, 2008.

OLIVEIRA, F. J. G. Políticas e planos territoriais nas escalas metropolitanas e regionais: análise das mudanças no Rio de Janeiro. In.: Anais do XIV encontro nacional da Anpur, Rio de Janeiro, Anpur, 2011.

OLIVEIRA, F. J. G. Reestruturação produtiva, território e poder no Rio de Janeiro. Rio de Janeiro : Garamond, 2008.

SANTOS, M. A natureza do espaço: técnica e tempo - razão e emoção. São Paulo: Hucitec, 1997.

SANTOS, M. O retorno do território. In: SANTOS, M. et al. (orgs.). Território: globalização e fragmentação. São Paulo: Hucitec, 1994.

SANTOS, M. Técnica, espaço, tempo: globalização e meio técnico-científico informacional. São Paulo: Hucitec, 1994a.

SANTOS, M. Metamorfoses do espaço habitado. 3ª ed.São Paulo: Hucitec, $1994 \mathrm{~b}$.

SANTOS, M. O papel ativo da geografia: um manifesto. Florianópolis: XII Encontro de geógrafos brasileiros, 1996.

\section{RESUMOS}

Ao longo das últimas décadas, território, economia e sociedade brasileiros têm sido profundamente atingidos por modernizações conduzidas pelo Estado em articulação com o capital privado nacional e internacional, no intuito de promover as condições necessárias ao desenvolvimento do capitalismo. Tendo como foco a metrópole do Rio de Janeiro e seu papel central na atual fase da acumulação de capital, visamos compreender a posição estratégica assumida por tais atores no que se refere ao planejamento do território, sublinhando a disseminação de empreendimentos produtivos e de sistemas de engenharia responsáveis pelos fluxos contemporâneos do capitalismo globalizado.

Dans les dernières décennies, le territoire, l'économie et la société du Brésil ont été fortement touchés par des œuvres de modernisation réalisées par l'État en partenariat avec des capitaux privés, nationaux ou internationaux, dans le but d'établir les conditions nécessaires au développement du capitalisme. En nous focalisant sur la métropole de Rio de Janeiro et son rôle central dans l'actuelle phase d'accumulation du capital, nous visons à comprendre les positions stratégiques prises par les différents acteurs sur ce qui concerne la planification du territoire, en soulignant la dissémination d'entreprises productives et de systèmes technologiques à la base des fluxes contemporains du capitalisme globalisé. 
In the last decades, the Brazilian territory, economy and society have been strongly concerned by modernization works realized by the State in partnership with national and international private capitals, to establish the conditions for the development of Capitalism. Focusing on the Rio de Janeiro metropolis and its pivotal role in the present phase of capitalism accumulation, we aim to understand the strategic positions assumed by the different actors on territorial planning, stressing the spreading of productive activities and technology systems which stands as a basis for the contemporary fluxes of the globalized Capitalism.

A lo largo de las últimas décadas, el territorio, la economía y la sociedad brasilera han sido profundamente afectados por las modernizaciones dirigidas por el Estado y articuladas al capital privado nacional e internacional con el objetivo de promover las condiciones necesarias para el desarrollo del capitalismo. Teniendo como foco la metrópoli de Río de Janeiro y su papel central en la actual fase de acumulación de capital, esperamos comprender la posición estratégica asumida por tales actores en lo referente a la planeación del territorio, subrayando la proliferación de proyectos productivos y de sistemas de ingeniería responsables por los flujos contemporáneos del capitalismo globalizado.

\section{ÍNDICE}

Palavras-chave: estado, território, metrópole, reestruturação produtiva, Rio de Janeiro

Palabras claves: estado, territorio, metrópoli, economía, re-estructuración

Keywords: state, territory, metropolis, economy, restructuring

Mots-clés: état, territoire, métropole, économie, restructuration

\section{AUTOR}

\section{REGINA CELI PEREIRA}

Professora da Universidade Estácio de Sá (UNESA) e da Fundação Educacional Unificadas Campograndense (FEUC). Email: rcp_regina@yahoo.com.br 